\title{
A New Mathematical Model for Multi Product Location-Allocation Problem with Considering the Routes of Vehicles
}

\author{
Hany Seidgar, Sahar Tadayoni Rad and Hamed Fazlollahtabar
}

\begin{abstract}
Facility location-allocation (FLA), which has been proved to be a valuable method in siting service facility, is widely used in real life, such as emergency service systems, telecommunication net works, public services, etc.FLA provides a valuable method in deciding where to place facilities coupled with determining how to assign demand to the located facilities in order to utilize resources effectively. This paper presents a new mathematical model for locating and allocating in transportation system in which each production center can produces multi type of products. The objective is to minimize the total costs in the production and transportation systems such as: fixed cost of opening the production centers, total production cost and total transportation cost that are entered to system by vehicles.
\end{abstract}

Keywords--- Location Allocation Problem, Vehicle Routing Problem, Multi Products System, Optimization

\section{INTRODUCTION AND LITERATURE REVIEW}

$\mathrm{L}$ OCATION a facility into the best place is a decision making L problem. The best place depends to the optimal distance, the capacity of the facility, optimal cost etc.Location allocation can be based on one criterion like optimal distance or adding various combinations of criteria, for example: distance and capacity of the facility together or capacity of the facility or optimal cost together and so on. Therefore, the goal of the location allocation problem is to obtain the best location or locations to fit one or more facilities.

Facility location-allocation (FLA) provides a valuable method in deciding where to place facilities coupled with determining how to assign demand to the located facilities in order to utilize resources effectively. This problem received much attention recently and was formulated as several kinds of models, such as continuous location models, network location models and mixed integer programming models.The vehicle routing problem (VRP) can be defined as finding optimal routes for a set of vehicles to serve some geographically scattered customers to minimize the total

Hany Seidgar, Department of Industrial Engineering, Mazandaran University of Science and Technology, Babol, Iran. E-mail: Hany_Seidgar@yahoo.com

Sahar Tadayoni Rad, Department of Industrial Engineering, K.N.Toosi University of Technology, Tehran, Iran.E-mail:S.Tadayonirad@yahoo.com

Hamed Fazlollahtabar, Faculty of Industrial Engineering, Iran University of Science and Technology, Tehran, Iran.E-mail:hfazl@iust.ac.ir

DOI: 10.9756/BIJIEMS.10348 operation cost, with each route starting and ending at the depot. VRP at first was discussed by Dantzig et al., [1]. In the traditional VRP, the vehicles are the servers for the customer locations and a customer requires only one task (or visit) by one vehicle.Min [2]was the first to introduce vehicle routing problem with simultaneous pickup and delivery (VRPSPD) for minimizing the total travel time of the route by considering the vehicle capacity as the problem constraint.As Perl and Daskin [3] pointed out, location routing problems involve three inter-related, fundamental decisions: where to locate the facilities, how to allocate customers to facilities, and how to route the vehicles to serve customers. The difference of the location routing problem from the classic vehicle routing problem is that not only routing must be designed but also, the optimal depot location must be simultaneously determined. The main difference between the location routing problem and the classical location - allocation problem is that, once the facility is located, the former requires a visitation of customers through tours while the latter assumes that the customer will be visited from the vehicle directly and, then, it will return to the facility without serving any other customer (Min et $a l .,[2])$. The location routing problem is very difficult to solve with the use of exact algorithms, especially if the number of customers or the candidate for location facilities are very large due to the fact that this problem belongs to the category of NP-hard problems, i.e. no polynomial time algorithms are known for their solution. However, a number of exact algorithms have been proposed for the solution of this problem solving mainly problems with a small number of locations and customers (Prins et al,.[4]; Russell et al., [5]).

Dethloff [6]and Tang and Galvano[7] (2006) then, contributed on mathematical reformulations. Berbeglia et al.,[8] also introduced a general framework to model static pickup and delivery problems. Jin $\mathrm{Ai}$ and Kachitvichyanukul[9]generalized the three existing formulation and reformulated the VRPSPD as a direct extension of basic VRP. In solution technique areas, Moshivio [10] studied PDP with divisible demands, in which each customer can be served by more than one vehicle, and presented greedy constructive algorithms based on tour partitioning. Salhi and Nagy[11] proposed four insertion-based heuristics, in which partial routes are constructed for some customers in basic steps and then the remaining customers will be inserted to the existing routes.Dohn et al., [12] studied the scheduling problem of ground handling tasks in some European airports. The problem requires manpower allocation with the consideration of time windows, job-teaming constraints, and a limited number of teams in order to 
maximize the total number of assigned tasks. Kim et al., [13]presented a combined vehicle routing and staff scheduling problem where a certain number of tasks has to be performed in a fixed sequence by a set of teams. The teams should be moved by a set of vehicles and the objective is to find an efficient schedule for the teams. They developed a mixed integer programming model for the problem that couldnot be solved optimally due to out of memory errors. Anyway, they developed a dispatching based heuristic algorithm to find feasible solutions for the generated problems. Ho and Leung [14] studied a manpower scheduling problem with job time windows and job-skills constraints. They considered an airline servicing operations before the flights take-off. Given the jobs to be serviced and the roster of workers for each shift, the problem is to form teams and assign them to the jobs, to service as many flights as possible.

This paper studies the location-allocation and vehicle routing problem. Each customer has several products. Demand of each customer for each product satisfied by production centers and rule of the vehicles that are existed in the each production center is to move the product to each customer.

\section{Problem Definition And Mathematical Model}

This paper considers location-allocation problem with multi product and routing of vehicles. Each production center can produce type of products. A new mathematical model for location-allocation problem with multiple productions is presented. The objective of the problem is to minimize the sum of location-allocation and vehicle routing costs.

The assumptions, indices, parameters and decision variables are introduced before developing the proposed mathematical model.

\section{A. Assumptions}

- There are number customers locating in known points.

- The travel distance between two nodes (customerproduction center and customer-customer) is calculated using the Euclidean distance.

- Customers may require multi products and it is possible for them to give of one or more production center in the system.

- Numbers of candidate production centers are predefined and there are several known vehicles to serve the customers in the system.

- Vehicles are different types based on their capacities and limitation on move the products to customers.

- Each vehicle can used in more than one tour and will be back to its own depot at the end of the tour.

- Demand of each customer is predefined for each product.

The structure of problem graphically illustrated in Figure 1.

\section{B. Indices}

- $j \quad$ index of customers $(j=1,2, \ldots N C)$

- $l \quad$ index of production centers $(l=1,2, \ldots, N P C)$

- $s \quad$ index of type of productions $(s=1,2, \ldots, N P)$

- $\quad k \quad$ index of vehicles $(k=1,2, \ldots, N V)$

\section{Parameters}

- NC Number of customers.

- NPC Number of production centers.

- NP Number of products (goods).

- $\quad$ NV Number of vehicles in transportation system.

- $\quad D_{s j}$ Demand of customer $j$ for product $s$.

- $\quad C a_{l}$ Production capacity of production center $l$.

- $\quad C v_{k}$ Capacity of vehicle $k$.

- $L B_{s l}$ Lower bound of product $s$ in production center $l$ if $l$ th production center opens for product $s$.

- $U B_{s l}$ Upper bound of product $s$ in production center $l$ if $l$ th production center opens for product $s$.

- $a_{s l}=$

1: if $l$ th production center can beproduced $s$ th product , otherwise 0 .

- $b_{k l}=$

1: if $k$ th vehicle exists in $l$ th production center, .otherwise 0 .

- $c_{k s}=$

1: if $k$ th vehicle can be trasport $s$ th product, otherwise 0 .

- $F_{s l} \quad$ Fixed cost of production $s$ if it producesin production center $l$.

- $\operatorname{Cost} 1_{s l}$ Production cost ofproduct $s$ in production center $l$.

- $\quad \operatorname{Cost} 2_{k}$ Routing cost of vehicle $k$.

\section{Decision Variables}

- $x_{k l s j}=$

1 : if $s$ th product transport from $l$ th production center

- $\quad$ to $j$ th customer by $k t h$ vehicl, otherwise 0 .

- $y_{k l s j}$ Amount of sth product that are transported from lth

- production center to $j$ th customer by $k t h$ vehicle.

- $z_{j l k}=$

1: if $k$ th vehicle loaded from $l$ th production center

- $\quad$ to $\mathrm{j}$ th customer, otherwise 0 .

- $w_{i j l k}=$

1: if $k$ th vehicle loaded of $l$ th production center moved

- from customer i to customer $\mathrm{j}$, otherwise 0 .

- $w_{l j k}^{\prime}=$

: if $k$ th vehicle came from $l$ th production center

- $\quad$ to customer $\mathrm{j}$, otherwise 0 .

- $w_{j l k}^{\prime \prime}=$

1: if $k$ th vehicle backed from customer $j$ to production

- $\quad$ center $l$, otherwise 0 .

- $\quad N_{s l}=$

1 : if $l$ th production center produced $s$ th product,

- otherwise 0 . 

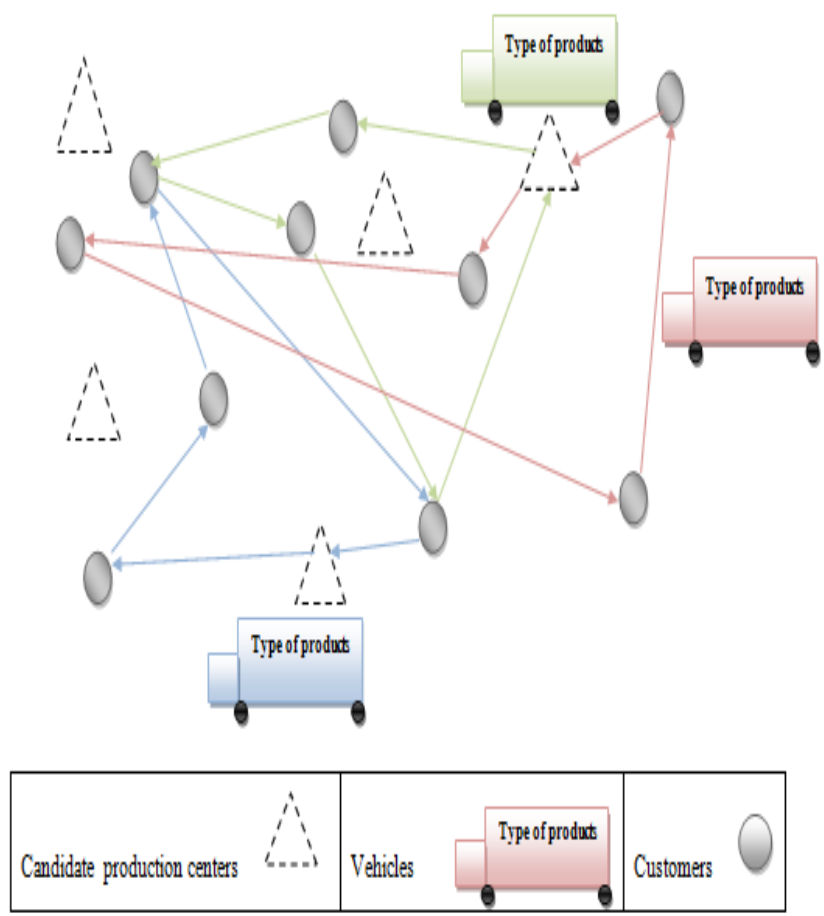

Figure 1: Structure of Location-Allocation Problem with Multi Products and Vehicle Routing Problem

\section{E. Mathematical Model}

$$
\begin{aligned}
& \sum_{l=1}^{N P C} \sum_{s=1}^{N P}\left(\operatorname{Cost} 1_{s l} \cdot\left[\sum_{j=1}^{N C} \sum_{k=1}^{N V} y_{k l s j}\right]+N_{s l} \cdot F_{s l}\right) \\
&+ \sum_{i=1}^{N C} \sum_{j=1}^{N C} \sum_{k=1}^{N V}\left(w_{l j k}^{\prime}+w_{j l k}^{\prime \prime}\right) \cdot \operatorname{Cost} 2_{k} \cdot d i s_{l j} \\
&+\sum_{i=1}^{N C} \sum_{j=1}^{N C} \sum_{k=1}^{N V} \sum_{l=1}^{N P C} w_{i j k l} \cdot \operatorname{Cost} 2_{k} \cdot d i s_{i j} \\
& x_{k l s j} \leq a_{s l} \cdot b_{k, l} \cdot c_{k s} \quad \forall k, l, s, j \\
& y_{k l s j} \geq x_{k l s j} \quad \forall k, l, s, j \\
& y_{k l s j} \leq M \cdot x_{k l s j} \forall k, l, s, j \\
& \sum_{k=1}^{N V} \sum_{l=1}^{N P C} y_{k l s j}=D_{s j} \quad \forall s, j \\
& \sum_{j=1}^{N C} \sum_{k=1}^{N V} \sum_{s=1}^{N P} n_{s}^{\prime} \cdot y_{k l s j} \leq C a_{l} \forall l \\
& \sum_{j=1}^{N C} \sum_{l=1}^{N P C} \sum_{s=1}^{N P} n_{s} \cdot y_{k l s j} \cdot b_{k l} \leq C v_{k} \forall k \\
& N_{s l} \leq a_{s l} \forall s, l \\
& \sum_{j=1}^{N C} \sum_{k=1}^{N V} y_{k l s j} \geq L B_{s l} \cdot N_{s l} \forall s, l \\
& \sum_{j=1}^{N C} \sum_{k=1}^{N V} y_{k l s j} \leq U B_{s l} \cdot N_{s l} \forall s, l
\end{aligned}
$$

$$
\begin{aligned}
& \sum_{j=1}^{N C} \sum_{k=1}^{N V} y_{k l s j} \leq \sum_{j=1}^{N C} D_{s j} \cdot N_{s l} \forall s, l \\
& z_{j l k} \geq \sum_{s=1}^{N P} y_{k l s j} \forall j, k, l \\
& z_{j l k} \leq M . \sum_{s=1}^{N P} y_{k l s j} \forall j, k, l \\
& w_{i j k l} \leq 0.5\left(z_{i l k}+z_{j l k}\right) \forall i, j, k, l \\
& w_{i j k l} \geq\left(z_{i l k}+z_{j l k}-1\right) \forall i, j, k, l \\
& w_{l j k}^{\prime} \leq z_{j k l} \forall j, k, l \\
& w_{l j k}^{\prime}+\sum_{i \neq j}^{N C} w_{i j k l}=z_{j l k} \forall j, k, l \\
& w_{j l k}^{\prime \prime}+\sum_{i \neq j}^{N C} w_{i j k l}=z_{j l k} \forall j, k, l \\
& s_{j l k} \geq s_{i l k}+1+M .(16) \\
& x_{k l s j}, z_{j k l}, w_{i j k l}, w_{j l k}^{\prime}, w_{j l k}^{\prime \prime}, N_{s l}=\{0,1\} \\
& y_{k l s j}, s_{j l k} \geq 0
\end{aligned}
$$

Objective value defines by Eq (1) that the objective is to minimize the total costs (Routing and production costs).Eq (2)causes to earn a feasible solution space for seeking the good solution based on ability of vehicles and production center for moving and producing them respectively. Esq (3)and(4) ensure that amount of products that are assigned to each customer and moved by each vehicle when are exist that there is created connection. Eq(5) guaranties each demand of each customer for each product satisfy by production centers that are in the production system. Eq (6) ensures that cannot produce at each production center more than their capacities. $\mathrm{Eq}(7)$ ensures that each vehicle cannot move bigger than their capacities at a tour of its route. Esq (8)-(11) ensure when a production line for a product can be ran that lower and upper bounds satisfied. Esq (12) and (13) help to identify the connection between customer-customer and customer production center. Esq (14)-(18) determine the route of each vehicle at each production center( tour of each vehicle). Restriction (19) is sub-tour elimination constraint set. Constraints (20) and (21) provide limits on the decision variables.

\section{NUMERICAL EXAMPLE}

In order to confirm that the mathematical model works as intended, an example is provided and the results of the execution with details of location-allocation of customers by vehicles are presented. Suppose that there are 5 customers, 4 vehicles, 2 products, 3 production centers, the demand of each customer for each product, cost of vehicle, capacity of each vehicle and production capacity of each production center are shown in Tables 1-13 and $n_{s}=n_{s}^{\prime}=1$. 
Table 1: Location of Customer of Example

\begin{tabular}{|c|c|c|c|c|c|}
\hline $\begin{array}{l}\text { Number of } \\
\text { customer }\end{array}$ & 1 & 2 & 3 & 4 & 5 \\
\hline$(\mathrm{X}, \mathrm{Y})$ & $(10,20)$ & $(15,30)$ & $(20,15)$ & $(18,25)$ & $(35,40)$ \\
\hline
\end{tabular}

Table 2: Location of Candidate Production Center of Example

\begin{tabular}{|l|c|c|c|}
\hline $\begin{array}{l}\text { Number of candidate } \\
\text { production center }\end{array}$ & 1 & 2 & 3 \\
\hline$(\mathrm{X}, \mathrm{Y})$ & $(10,20)$ & $(15,30)$ & $(20,15)$ \\
\hline
\end{tabular}

Table 3: Capacity of Production Centers of Example

\begin{tabular}{|l|l|l|l|}
\hline Number of production center & 1 & 2 & 3 \\
\hline Production capacity & 200 & 300 & 500 \\
\hline
\end{tabular}

Table 4: Capacity of Vehicles of Example

\begin{tabular}{|l|l|l|l|l|l|l|}
\hline $\begin{array}{l}\text { Number of } \\
\text { vehicle }\end{array}$ & 1 & 2 & 3 & 4 & 5 & 6 \\
\hline $\begin{array}{l}\text { Capacity of } \\
\text { vehicle }\end{array}$ & 50 & 100 & 150 & 50 & 200 & 150 \\
\hline
\end{tabular}

Table 5: Fixed Cost for Opening Production Line of a Product at a Production Center of Example

\begin{tabular}{|l|c|c|c|}
\hline & $\begin{array}{c}\text { Production } \\
\text { center } 1\end{array}$ & $\begin{array}{c}\text { Production } \\
\text { center } 2\end{array}$ & $\begin{array}{c}\text { Production } \\
\text { center3 }\end{array}$ \\
\hline Product 1 & 500 & 400 & 300 \\
\hline Product 2 & 400 & 350 & 300 \\
\hline
\end{tabular}

Table 6: Possibility for Producing a Product at a Production Center

\begin{tabular}{|l|l|l|l|}
\hline & $\begin{array}{l}\text { Production } \\
\text { center } 1\end{array}$ & $\begin{array}{l}\text { Production } \\
\text { center 2 }\end{array}$ & $\begin{array}{l}\text { Production } \\
\text { center3 }\end{array}$ \\
\hline Product 1 & 1 & 1 & 0 \\
\hline Product 2 & 1 & 1 & 1 \\
\hline
\end{tabular}

Table7: Lower Bound of a Product at a Production Center of Example

\begin{tabular}{|l|c|c|c|}
\hline & $\begin{array}{c}\text { Production } \\
\text { center } 1\end{array}$ & $\begin{array}{c}\text { Production } \\
\text { center } 2\end{array}$ & $\begin{array}{c}\text { Production } \\
\text { center3 }\end{array}$ \\
\hline Product 1 & 40 & 30 & 50 \\
\hline Product 2 & 20 & 40 & 30 \\
\hline
\end{tabular}

Table 8: Upper Bound of a Product at a Production Center of Example

\begin{tabular}{|l|c|c|c|}
\hline & $\begin{array}{c}\text { Production } \\
\text { center } 1\end{array}$ & $\begin{array}{c}\text { Production } \\
\text { center 2 }\end{array}$ & $\begin{array}{c}\text { Production } \\
\text { center3 }\end{array}$ \\
\hline Product 1 & 200 & 150 & 100 \\
\hline Product 2 & 300 & 350 & 200 \\
\hline
\end{tabular}

Table 9: Demand of Each Customer for Each Product

\begin{tabular}{|c|c|c|c|c|c|}
\hline & $\begin{array}{l}\text { Custome } \\
\text { r } 1\end{array}$ & $\begin{array}{l}\text { Custome } \\
\text { r } 2\end{array}$ & $\begin{array}{l}\text { Custome } \\
\text { r } 3\end{array}$ & $\begin{array}{l}\text { Custome } \\
\text { r } 4\end{array}$ & $\begin{array}{l}\text { Custome } \\
\text { r } 5\end{array}$ \\
\hline $\begin{array}{l}\text { Produc } \\
\text { t } 1\end{array}$ & 80 & 40 & 35 & 50 & 90 \\
\hline $\begin{array}{l}\text { Produc } \\
\text { t } 2\end{array}$ & 100 & 30 & 25 & 35 & 20 \\
\hline
\end{tabular}

Table 10: Producing Cost of a Product at a Production Center

\begin{tabular}{|l|l|c|c|}
\hline & \multicolumn{2}{|l|}{$\begin{array}{l}\text { Production } \\
\text { center 1 }\end{array}$} & \multicolumn{2}{|l|}{$\begin{array}{l}\text { Production } \\
\text { center 2 }\end{array}$} & $\begin{array}{l}\text { Production } \\
\text { center3 }\end{array}$ \\
\hline Product 1 & 2 & 4 & 1 \\
\hline Product 2 & 2 & 3 & 2 \\
\hline
\end{tabular}

Table 11: Cost of Vehicle

\begin{tabular}{|c|c|c|c|c|c|c|}
\hline $\begin{array}{c}\text { Number of } \\
\text { vehicle }\end{array}$ & 1 & 2 & 3 & 4 & 5 & 6 \\
\hline $\begin{array}{c}\text { Capacity of } \\
\text { vehicle }\end{array}$ & 15 & 20 & 30 & 40 & 5 & 15 \\
\hline
\end{tabular}

Table12: Exiting Possibility for Each Vehicle of each Production Center

\begin{tabular}{|c|c|c|c|}
\hline & $\begin{array}{l}\text { Production } \\
\text { center } 1\end{array}$ & $\begin{array}{l}\text { Production } \\
\text { center } 2\end{array}$ & $\begin{array}{l}\text { Production } \\
\text { center3 }\end{array}$ \\
\hline Vehicle 1 & 1 & 0 & 0 \\
\hline Vehicle 2 & 0 & 0 & 1 \\
\hline Vehicle3 & 1 & 0 & 0 \\
\hline Vehicle4 & 0 & 1 & 0 \\
\hline Vehicle 5 & 0 & 1 & 0 \\
\hline Vehicle 6 & 1 & 0 & 0 \\
\hline
\end{tabular}

Table 13: Ability of Each Vehicle for Moving Each Product

\begin{tabular}{|l|c|c|}
\hline & Product1 & Product2 \\
\hline Vehicle 1 & 1 & 0 \\
\hline Vehicle 2 & 1 & 1 \\
\hline Vehicle3 & 0 & 1 \\
\hline Vehicle4 & 1 & 1 \\
\hline Vehicle 5 & 1 & 0 \\
\hline Vehicle 6 & 1 & 1 \\
\hline
\end{tabular}

The objective is to minimize the total costs (Routing and production costs).The following Figure illustrates local solution obtained of solution space in details from the mathematical model. Figure2 illustrates locations 1, 2 and 3 open to satisfy demands of the customers in the system production. Vehicles 1 and 6 at the first production center, vehicles 4 and 5 at the second production center and finally vehicle 2 at the third production center moved of the production centers to satisfy the demands of the existing customers. Vehicles1,4,5 and 6 load 50, 40, 200 and 5 units respectively of product 1 to sent them to their customers and vehicles 2 and 6 load 65 and 145 units of product 2 to satisfy the demand of the customers in the system production. Amount of the demands that are satisfied by each vehicle at the each production center are shown in Table 14. Also, based on the solutions that are obtained by solving the mathematical model, production line for producing product 1 is activated at the centers 1 and2. At the production center 3 only activates production line2. 


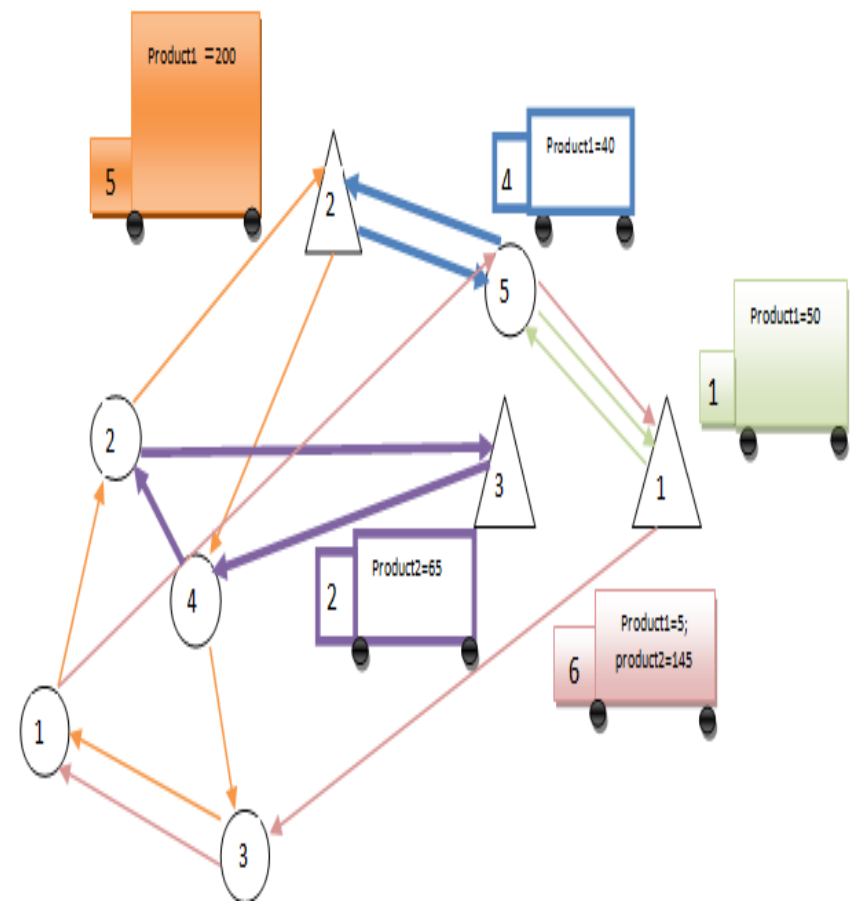

Figure 2: Presentation of the Solution Graphically

As it can be seen in Figure 2 and the Table 14 , the objective value is equal to 5923.785 .

Table 14: Amount of the Each Product that are Transported by Each Vehicle to Each Customer

\begin{tabular}{|c|c|c|c|}
\hline $\begin{array}{c}\text { Decision } \\
\text { Variable }\end{array}$ & $\begin{array}{c}\text { Value of the } \\
\text { decision variable }\end{array}$ & $\begin{array}{c}\text { Decision } \\
\text { Variable }\end{array}$ & $\begin{array}{c}\text { Value of the } \\
\text { decision variable }\end{array}$ \\
\hline$y_{1115}$ & 50 & $y_{5213}$ & 30 \\
\hline$y_{2322}$ & 30 & $y_{5214}$ & 50 \\
\hline$y_{2324}$ & 35 & $y_{6113}$ & 5 \\
\hline$y_{4215}$ & 40 & $y_{6121}$ & 100 \\
\hline$y_{5211}$ & 80 & $y_{6123}$ & 25 \\
\hline$y_{5212}$ & 40 & $y_{6125}$ & 20 \\
\hline
\end{tabular}

\section{CONCLUSION AND FUtURE ENHANCEMENT}

In this paper a new mathematical model is presented for locating and allocating candidate production center with considering the route of vehicles. The objective was to minimize the total costs in the transportation and production systems. This problem is Np-hard, therefore it is worthwhile to apply meta-heuristic algorithms to find the good solution in the solution space. Drivers have significant rule for traveling the products by vehicles, the competency of drivers can be considered for future research.

\section{REFERENCES}

[1] G Dantzig, J. H Ramser, The truck dispatching, problem, Management Science,vol. 6, pp. 80-91, 1959.

[2] H Min, V Jayaraman, R Srivastava, Combined location-routing problems: a synthesis andfuture research directions. European. Journal ofOperation Research, vol.108, pp. 1-15, 1998.

[3] J Perl, M.S Daskin, A warehouse location routing model. Transportation Research. Vol.19,pp. 381-396, 1985.

[4] C Prins, C Prodhon, R.W Calvo, A memetic algorithm with population management(MA|PM) for the capacitated location-routing problem. In:
Evolutionary Computation CombinatorialOptimization. LNCS, vol. 906, pp. 183-194, 2006.

[5] R Russell, W.C Chiang, D Zepeda, Integrating multi-product production and distribution innewspaper logistics, Computer \& Operation Research,vol.35,Issue.5,pp.1576-1588,2008.

[6] J Dethloff, Vehicle routing and reverse logistics: The vehicle routing problem with simultaneous delivery and pick-up. OR Spektrum, vol.23, pp.79-96,2001.

[7] F. A Tang Montane, R.D Galvão , A tabu search algorithm for the vehicle routing problem with simultaneous pick-up and delivery service, Computers \& Operations Research, vol.33, Issue.3,pp.595-619,2006.

[8] G Berbeglia, J.F Cordeau, I Gribkovskaia, G Laporte, Static pickup and delivery problems: A classification scheme and survey. TOP, vol.15, Issue.1,pp. 1-31, 2007.

[9] T. A Jin, VKachitvichyanukul, A particle swarm optimization for the vehicle routing problem with simultaneous pickup and delivery, Computers \& Operations Research, vol.36, pp.1693 - 1702,2009.

[10] G Mosheiov, Vehicle routing with pick-up and delivery: tourpartitioning heuristics. Computer \& Industrial Engineering, vol.34,Issue.3,pp. 669-684, 1998.

[11] G Nagy, S Salhi, Heuristic algorithms for single and multiple depot vehicle routing problems with pickups and deliveries.European Journal of Operational Research, vol.162, Issue1,pp. 126-141, 2005.

[12] A Dohn, E Kolind, J Clausen, The manpower allocation problem with time windows and job-teaming constraints: A branch-and-price approach.Computers \& Operations Research, vol.36, pp.1145-1157, 2009.

[13] B.I Kim, J Koo, J Park, The combined manpower-vehicle routing problem for multi-staged services, Expert Systems with Applications,vol. 37, pp. 8424-8431, 2010.

[14] S.C Ho, J.M Leung, Solving a manpower scheduling problem for airline catering using metaheuristics,European Journal of Operational Research, vol. 202, pp.903-921, 2010.

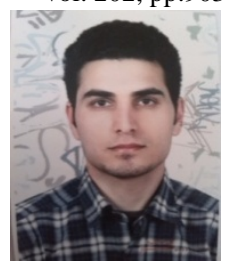

Hany Seidgar received his MSC in Industrial engineering from Mazandaran University of Science and Technology. His research interests include Optimization in manufacturing systems, Scheduling and planning, Vehicle Routing Problems, MetaHeuristic and heuristics algorithms. He has published in several international journals and conferences. (Email:Hany_Seidgar@yahoo.com)

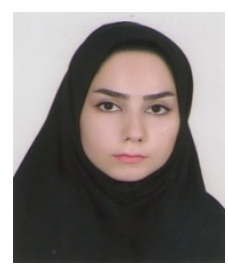

Sahar Tadayoni Rad received her MSC in Industrialengineering from K.N. Toosi University of Technology. Her research interests include Optimization in manufacturing systems, Scheduling and planning. She has published several papers in international journals and conferences. (Email:S.Tadayonirad@gmail.com)

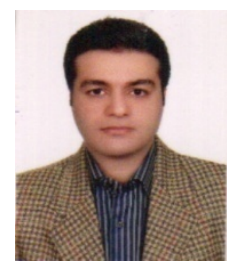

Hamed Fazlollahtabar has been graduated in MSc of Industrial Engineering at Mazandaran University of Science and Technology, Babol, Iran. He received Doctorate awarded from the Gulf University of Science and Technology in Quantitative Approaches in Electronic Systems. Currently he is studying $\mathrm{PhD}$ of Industrial Engineering at Iran University of Science and Technology, Tehran, Iran. He is in the editorial board of WASET (World Academy of Science Engineering Technology) Scientific and Technical Committee on Natural and Applied Sciences, reviewer committee of International Conference on Industrial and Computer Engineering (CIE), and member of the International Institute of Informatics and Systemics (IIIS). He has become a member of Iran Elite Council. His research interests are mathematical modeling, optimisation in knowledge-based systems and manufacturing systems. He has published over 160 research papers in international book chapters, journals and conferences 